\title{
Research on the Impact of Opening Enclosed Residential Community to Traffic
}

\author{
Zhaoyuan Wang ${ }^{1, \text { a }}$ \\ ${ }^{1}$ North China Electric Power University (Baoding), Baoding 071000, China \\ a2522635788@qq.com
}

Keywords: enclosed residential community, TOPSIS analysis, road capacity

Abstract. First of all, this paper establishes evaluation index system, by collecting relevant indexes. And then, we analyze the impact of opening enclosed residential community to every index. Then, we establish the comprehensive model of evaluation to evaluate an opening enclosed residential community in Changsha. Finally, we make suggestions about opening enclosed residential community.

\section{Introduction}

With the State Council promoting the policy of city block, it has become a hit that opening enclosed residential community can whether improve the structure of transportation network and traffic condition or not. It's important to study on this issue.

\section{Road capacity evaluation index system}

The evaluation index system should fully reflect the impact of opening enclosed residential community. So we take the structure of residential community and the surrounding roads into consideration. In this paper, we set up the following index system.

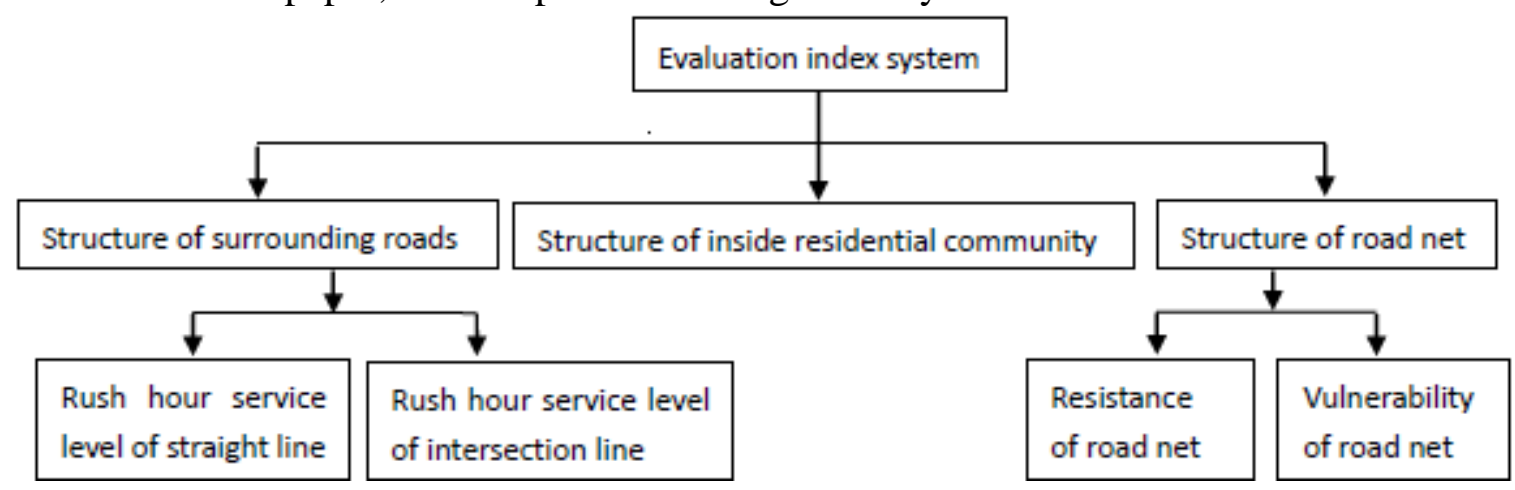

Fig. 1 The evaluation index system

Opening enclosed residential community works on surrounding road net, which has an effort on the service level of surrounding road net. However, there are many indexes to describe it. In this paper we choose the saturability of straight line and the delay time of intersection line as the evaluation indexes.

\section{Calculation of every evaluation index}

\section{Saturability of straight line ${ }^{[1]}$.}

The service level of road is reflected by the road saturability, which is the ratio of every road capacity and the sum of all road capacity. The formula for calculation follows.

$$
N_{j 1}=\sum_{i=1}^{m_{1}} \frac{V_{1 i}}{S_{1 i}} \cdot \frac{V_{1 i}}{\sum_{i=1}^{m_{1}} S_{1 i}}
$$


Among it, $v_{1 i}$ stands for traffic volume of the road net in rush hour. $\mathbf{s}_{1 \mathrm{i}}$ stands for road capacity of this net. $\mathrm{m}_{1}$ stands for sum of the road in the road net.

Average delay time of intersection line ${ }^{[2]}$.

Supposing that the lane delay happens randomly, we can calculate every lane delay by using following formula.

$$
\mathrm{d}=0.38 T_{c} \frac{\left(1-\frac{g}{T_{c}}\right)}{\left[1-\left(\frac{g}{T_{c}}\right) x\right]}+173 X^{2}(X-1)+\sqrt{(X-1)^{2}+\frac{16 X}{c}}
$$

Among it, d stands for average lane delay to every vehicle. $T_{c}$ is cycle. $\frac{g}{T_{c}}$ stands for lane split. $\mathrm{X}$ stands for lane saturability. C stands for lane capacity. V stands for traffic volume.

$$
d_{A}=\frac{\sum d_{i} V_{i}}{\sum V_{i}}
$$

Among it, $d_{A}$ stands for delay of road A. $d_{i}$ stands for delay of lane I in road A. $V_{i}$ stands for traffic volume of lane i.

Vulnerability of road net ${ }^{[3]}$.

Roads in enclosed residential community and surrounding roads can be regarded as two independent running system, so the effect between them can be overlooked. After opening enclosed residential community, roads in it integrate into road net as a whole, it must make a difference to the road net. Vulnerability of road net is the decreasing degree of road net service level. Therefore, this paper regards variance of net node degree as the index to evaluate the vulnerability of road net. The net node degree is the number of side connected to the node. The formula for calculation follows.

$$
\begin{gathered}
\mathrm{N}_{j 3}=\frac{1}{\mathrm{~L}} \sum_{\mathrm{i}=1}^{\mathrm{L}}\left(\mathrm{k}_{\mathrm{i}}-\overline{\mathrm{k}}\right)^{2} \\
\overline{\mathrm{k}}=\frac{1}{\mathrm{~L}} \sum_{\mathrm{i}=1}^{\mathrm{L}} \mathrm{k}_{\mathrm{i}}
\end{gathered}
$$

\section{Resistance of road net.}

According to Braess paradox, if we don’t take the demand of going out and the road chose by pedestrian and build roads, it will decrease the whole road capacity, so that pedestrian will take more time in walking through the road net. In research, we use resistance of road net to quantify and analyze this situation. So the resistance of road net follows.

$$
\begin{aligned}
N_{j 4} & =\sum_{(i, j \in P)} t_{i j} f_{i j} \\
\mathbf{t}_{\mathrm{ij}} & =\mathbf{e}_{\mathrm{ij}}+\mathbf{x}_{\mathrm{ij}} \mathrm{f}_{\mathrm{ij}}
\end{aligned}
$$

Among it , $e_{i j}$ stands for time going through road $i j$ freely. $x_{i j}$ stands for resistance coefficient of road $\mathrm{ij} . \mathrm{f}_{\mathrm{ij}}$ stands for volume of traffic in every road.

\section{Comprehensive appraisal model based on TOPSIS analysis ${ }^{[4]}$}

First of all, get the normal decision matrix about four quantitative indexes using method of vector programming. We set the decision matrix of multiple attribute decision making problem as $\mathrm{A}=\left(N_{i j}\right)$ ${ }_{m \times n}$ and the normalized decision matrix as $\mathrm{B}=\left(b_{i j}\right)_{m \times n}$.Among it,

$$
\mathrm{b}_{i j}=N_{i j} / \sqrt{\sum_{i=1}^{m} N_{i j}^{2}}, \quad \mathrm{i}=1,2, \cdots, \mathrm{m} ; \mathbf{j}=1,2, \cdots, \mathrm{n}
$$

Then, we set weighted normalized matrix as $\mathrm{C}=\left(\mathrm{c}_{i j}\right)_{m \times n} \cdot \mathrm{w}=\left[\mathrm{w}_{1}, w_{2}, \cdots, w_{n}\right]^{T}$ stands for the weighted vector given by decision maker. So, $c_{i j}=w_{j} \cdot b_{i j}$, i=1,2, $\cdots, \mathrm{m} ; \mathrm{j}=1,2, \cdots, \mathrm{n}$.

After that, we calculate positive ideal solution $C^{*}$ and negative ideal solution $C^{0}$. We $\operatorname{set} \mathrm{c}_{j}^{*}$ as the jth attribute value in positive ideal solution $C^{*}$ and $c_{j}^{0}$ as the jth attribute value in negative ideal solution $C^{0}$.So, 


$$
\begin{aligned}
& \text { Positive ideal solution } c_{j}^{*}=\left\{\begin{array}{l}
\max _{i} c_{i j}, j \text { is the benefit attribute value, } \\
\min _{\mathrm{i}} c_{i j}, \mathrm{j} \text { is the cost attribute value, }
\end{array}\right. \\
& \text { Negative ideal solution } c_{j}^{0}=\left\{\begin{array}{l}
\min _{\mathrm{i}} c_{i j}, \mathrm{j} \text { is the benefit attribute value, } \\
\max _{\mathrm{i}} c_{i j}, \mathrm{j} \text { is the cost attribute value, }
\end{array}\right.
\end{aligned}
$$

And then, we calculate distance between every positive ideal solution and negative ideal solution. The distance between alternative $d_{i}$ and positive ideal solution is

$$
\mathrm{g}_{i}^{*}=\sqrt{\sum_{j=1}^{n}\left(c_{i j}-c_{j}^{*}\right)^{2}}, \mathrm{i}=1,2, \cdots, \mathrm{m}
$$

The distance between alternative $d_{i}$ and negetive ideal solution is

$$
\mathrm{g}_{i}^{0}=\sqrt{\sum_{j=1}^{n}\left(c_{i j}-c_{j}^{0}\right)^{2}}, \mathrm{i}=1,2, \cdots, \mathrm{m}
$$

Finally, we calculate ranking index value of every plan, which is

$$
f_{i}^{*}=\mathrm{g}_{i}^{0} /\left(\mathrm{g}_{i}^{0}+\mathrm{g}_{i}^{*}\right), \mathrm{i}=1,2, \cdots, \mathrm{m}
$$

According to the value of $f_{i}^{*}$, we get the comprehensive evaluation value before opening enclosed residential community and after. So, we draw the conclusion whether opening enclosed residential community is beneficial or not.

\section{Evaluation based on opening enclosed residential community in Changsha ${ }^{[5]}$}

We classify residential community based on the inside road structure of it. The residential community is divided roughly into three types, namely tree-shaped, ring-shaped and mesh. In this paper, we choose a tree-shaped enclosed residential community in Changsha to evaluate the impact of opening enclosed residential community to traffic. By analyzing roads surrounding the enclosed residential community in Changsha, we draw the map with the method of straight line instead of curve. The map follows.

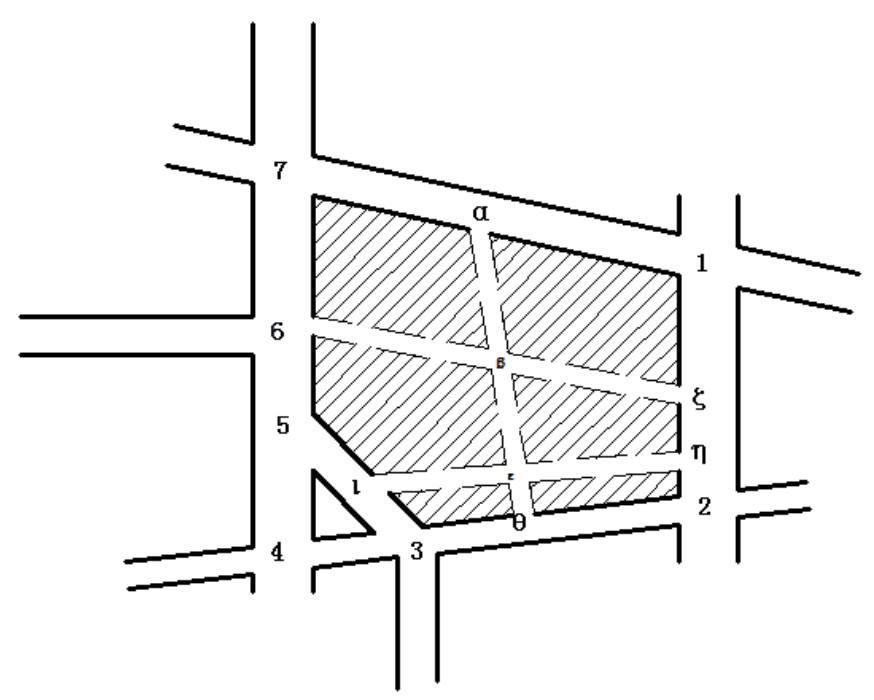

Fig. 2 The map of the enclosed residential community in Changsha

By calculating every evaluation index, we get the following results of before opening enclosed residential community and after. 
Table 1 Comparison between before opening enclosed residential community and after

\begin{tabular}{ccc}
\hline \hline & $\begin{array}{c}\text { Before opening enclosed } \\
\text { residential community }\end{array}$ & $\begin{array}{c}\text { After opening enclosed } \\
\text { residential community }\end{array}$ \\
Saturability of straight line & 71.61621 & 69.81757 \\
Average delay time of & 36.09 & 30.85 \\
intersection line & & \\
Vulnerability of road net & 0.204082 & 0.168368 \\
Resistance of road net & 239.8412 & 287.5757 \\
\hline \hline
\end{tabular}

\section{Summary}

By comparing the results, we knows that opening enclosed residential community makes saturability of straight line down, average delay time of intersection line down, vulnerability of road net down and resistance of road net up. We plug these results into the TOPSIS evaluation index system, so that we can learn that $f_{1 \mathrm{~b}}^{*}=0.3642, f_{1 \mathrm{a}}^{*}=0.6358$. So, we can draw the conclusion that as for tree-shaped enclosed residential community, opening is much better than closing to surrounding traffic.

\section{References}

[1]. Zhonghua Shang, Research of the traffic impact analysis of residential community[D] Master Degree Dissertation of Chang'an University, 2006.2,p.41.

[2]. Jingjin Yuan, Zhenzhou Yuan, Analysis of signal intersection service level evaluation system indexes and its application[J] Technology of highway and transport, 2006.8,p.146-147.

[3]. Bin Zhan, Ruidong Cai, Yuancheng Hu, Mengxin Cao, Residential community open-up strategy based on fragility of urban road network[J] Technology and method, 2016.7,p.99-100.

[4]. Shoukui Si, Zhaoliang Sun, Mathematical modeling algorithm and application[M] Nation defense industry press, 2015.4,p.369-370.

[5]. Xiangpeng Li, Urban traffic congestion countermeasures-opening research of enclosed type district traffic[D] Master Degree Dissertation of Changsha University of Science \& Technology, 2014.4,p. 57-68. 